\title{
Optimal Placement of Distributed Generation to Enhance Bus Voltage Qualitative Index
}

\author{
Shah Mohazzem Hossain ${ }^{1 *}$, Abdul Hasib Chowdhury ${ }^{2}$ \\ ${ }^{1}$ Department of EECE, Military Institute of Science \& Technology (MIST), Dhaka, Bangladesh \\ ${ }^{2}$ Departmentof EEE, Bangladesh University of Engineering \& Technology (BUET), Dhaka, Bangladesh \\ Corresponding Email: ${ }^{*}$ soneteee@gmail.com, ${ }^{2}$ hasib@eee.buet.ac.bd
}

\begin{abstract}
The installation of distributed generation (DG) units in power distribution networks is becoming more prominent. The impact of DG units on the voltage qualitative index has become significant day by day. Optimization techniques are tools which can be used to locate the DG units in the system, so as to utilize these units optimally within certain limits and constraints. Thus, the impacts of DG unit's issues, such as voltage qualitative index and voltage profile, can be analyzed effectively. The ultimate goal of this paper is to propose a method of locating DG units so as to improve the voltage qualitative index. The load and renewable DG generation of only active power supply with probabilistic nature are considered in this study. The proposed method starts by selecting candidate buses into which to install the DG units on the system, prioritizing buses which are sensitive to voltage profile and thus improve the voltage qualitative index. The DG units' placement is formulated using nonlinear programming method with an objective function of improving the voltage qualitative index corresponding to then individual bus voltage enhancement where the constraints are the system voltage limits, current limits, systems load demand and the DG penetration level.
\end{abstract}

\section{Introduction}

Distributed generation is an emerging approach in the electric power generation where power can be produced near the place of use generally these resources can either be grid connected or independent of the grid the generating plant is connected directly to grid at distribution level voltage or on the meter in the customer side it includes engine small and micro turbines, fuel cells and concentrating solar and photo voltaic cells the range of power produced from distributed generation varies from less than a kilowatt(kW) to megawatt(MW) based on the size of distributed generation unit. The DG can be classified into different types based on the application for which they are used some of the applications are standby, standalone, peak load-shaving, remote applications and base load the DG size are not restricted and depends on the user type and it varies from one unit to large number of units [1]. One major problem faced by all the developing countries today is meeting the increasing power demand. Depletion of non-renewable energy sources is making them look at better alternatives like the renewable energy sources. But even by the use of most effective techniques available today, our efficiency in utilizing them is far low compared to the non-renewable energy sources [2]. So engineers are working on better utilization of present system. As the society's dependency on electrical energy is greater than ever and will keep increasing in the future, the analysis of a distribution system is an important area of study because distribution system along with providing the vital link between the bulk power system and the consumers is the major source of power loss. Typically, if the total power loss in the whole system is about $25 \%$, the distribution system claims about $17 \%$ of the total loss whereas the transmission system claims only $8 \%$ [3]. So reducing the power loss in the distribution system is of major importance. A distribution circuit normally contains primary or main feeders and lateral distributors. A main feeder originates from the distribution substation and passes through the major load centers [4-5]. Lateral distributors connect the individual transformers at their ends. Many distribution systems used in practice have a single circuit main feeder and are defined as radial distribution systems. Radial distribution systems are popular because of their simple design and generally low cost. The distribution generation can be treated as power compensation. Due to local injection of active power by the distribution generator unit, current in the feeders comes down reducing power loss and thereby improving the voltage profile. Power loss reduction, environmental friendliness, voltage improvement, and increased reliability are some advantages of DG-unit application [6]. 


\section{Bus Voltage Qualitative Index}

The installation of DG units in systems originally radial and designed to operate without any generation on the distribution system, can significantly impact the power flow and voltage conditions at both, customers and utility equipment. Voltage variability stems from the load dynamics to restore power consumption beyond the capability of the combined transmission and generation system [7-8]. Main reason for voltage variability are the high load variation in network system, large distance between load to source and low source voltage. This paper presents analytical methods to determine the optimal location to place a DG in radial as well as networked systems to maximize the power loss of the system. The objective function for the DG placement problem is needed to meet certain security constraints and network constraints. Network balance equation must be satisfying during all possible load variation with demand and supply. Electrical network contains some imperative constraints like bus voltage, thermal current limits of each bus and power limits of connected DG. Multi-objective noncommensurable functions with these number of equality and inequality constraints are being optimized for the DG placement in the power system network.

$$
\text { Optimize } F(x)=f \times \max V_{\text {bus }}(x)
$$

Where, $F(x)=$ Optimized function

$V_{\text {bus }}(x)=$ Improved bus voltage index\&

$f=$ Bus voltage quality factor

As the current entering a bus is considered positive and leaving the bus is negative that causes correspondingly the real power and reactive power entering that bus is positive and negative. The complex power at bus-i of Fig. 1 is then given by [9],

$$
P_{i}-j Q_{i}=V_{i}^{*} I_{i}=V_{i}^{*} \sum_{k=1}^{n} Y_{i k} V_{k}
$$

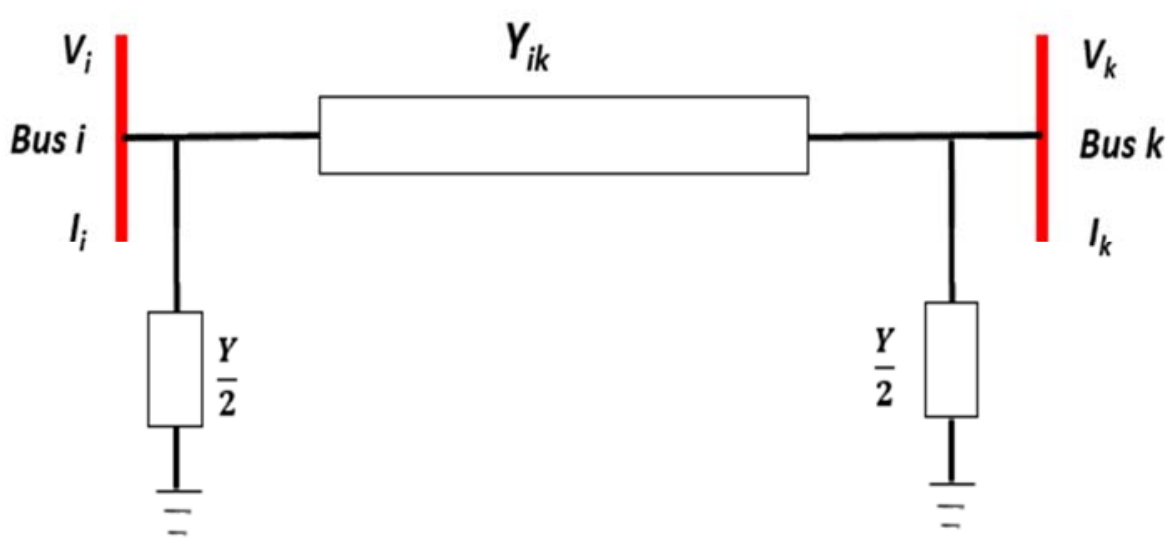

Fig. 1 Basic power system network

Bus voltage profile is analysed by gauss-seidal load flow study where updated bus voltage profile value is determined in following way from the complex power equation.

$$
V_{i}=\frac{1}{Y_{i i}}\left[\frac{P_{i}-j Q_{i}}{V_{i}^{*}}-Y_{i 1} V_{1}-Y_{i 2} V_{2}-Y_{i 3} V_{3}-\cdots \cdots \cdots-Y_{i n} V_{n}\right]
$$

Updated final total bus voltage of all node buses is represented by, $\quad \max V_{\text {Bus }}=\sum_{i=1}^{N_{\text {bus }}} V_{i}$ If there are $\mathrm{N}$ number of buses,

$$
\text { Max } V_{\text {Bus }} \text { Index }=\frac{\sum_{i=1}^{N_{b u s}} V_{i}}{N}
$$

By using standard deviation of the given system,

$V_{\text {Bus }}$ deviation index, $d=\sqrt{\frac{\sum\left(V_{\text {index }}-\bar{V}\right)^{2}}{N}}$

Bus voltage quality factor, $f=1$ - $d$ 


\section{System Optimization}

A power-flow study usually uses simplified notation such as a one-line diagram and per-unit system and focuses on various forms of AC power (i.e.: voltages, voltage angles, real and reactive power). It analyses the power systems abnormal steady-state operation. Load flow studies are performed on power systems to understand the nature of the installed network and to determine the static loading performance of the system.

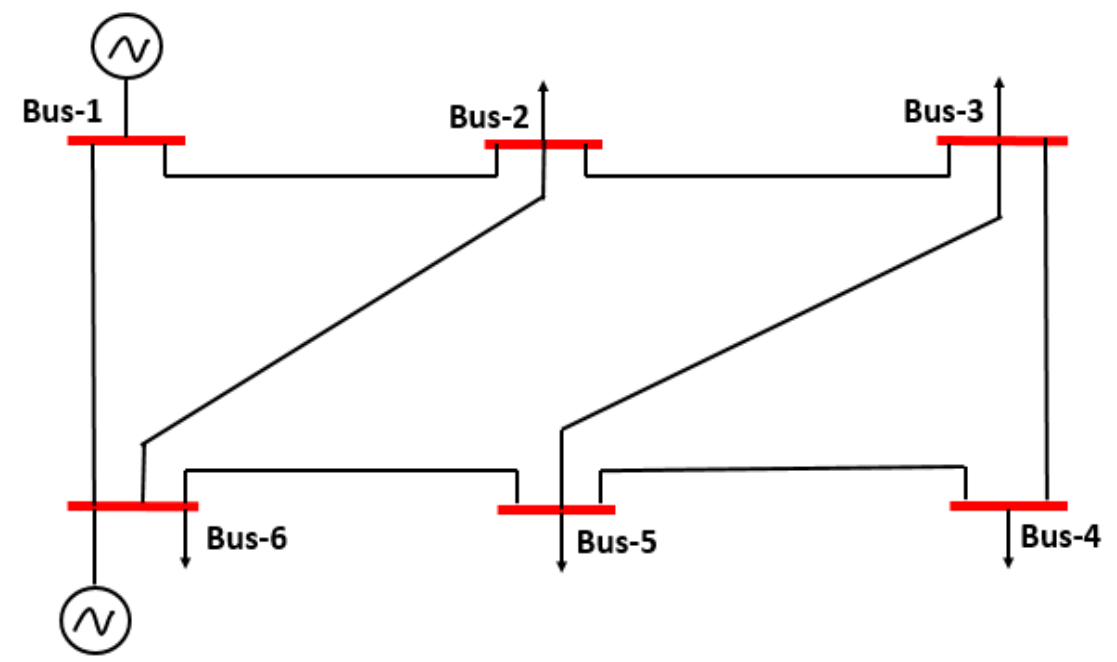

Fig. 2 IEEE-6 bus system network

In the research, multi-objective optimal placement problem is decomposed into different types of real time variable functions. The developed algorithm in MATLAB for these variables of N-bus system is implemented in IEEE- 6 bus test systems of Fig. 2. Bus-1 is selected as the slack bus while bus-6is the corresponding generator $(P V)$ bus, except all are load $(P Q)$ buses. The line impedances with the line charging admittances, bus voltage magnitudes and installed generator details rating of the network is shown in Table 1 to Table 2.

Table 1. Line impedances and line charging admittances

\begin{tabular}{ccc}
\hline Line (bus to bus) & $\begin{array}{c}\text { Impedance (Per } \\
\text { unit) }\end{array}$ & Line Charging (Y/2) \\
\hline $1-2$ & $0.025+j 0.10$ & $j 0.030$ \\
$1-6$ & $0.047+j 0.25$ & $j 0.020$ \\
$2-3$ & $0.050+j 0.25$ & $j 0.025$ \\
$2-6$ & $0.045+j 0.25$ & $j 0.023$ \\
$3-4$ & $0.040+j 0.20$ & $j 0.020$ \\
$3-5$ & $0.048+j 0.24$ & $j 0.015$ \\
$4-5$ & $0.080+j 0.42$ & $j 0.010$ \\
$5-6$ & $0.100+j 0.50$ & $j 0.050$ \\
\hline
\end{tabular}

Table 2 Bus voltage magnitudes and generator rating

\begin{tabular}{ccccc}
\hline \multirow{2}{*}{ Bus No. } & \multicolumn{2}{c}{ BusVoltage } & \multicolumn{2}{c}{ Power Generated } \\
\cline { 2 - 5 } & Magnitude (pu) & Angle (deg) & $P($ MW) & $Q$ (MVAR) \\
1 & 1.05 & - & 30 & - \\
6 & 1.02 & - & 20 & - \\
DG & 1.00 & - & 2 & - \\
\hline
\end{tabular}

The operation of power systems has been complicated by the rapid diversification of loads in recent days. The load on a power system varies from time to time due to uncertain demands of the consumers and is known as variable load on the station. A power station is designed to meet the load requirements of the consumers. An ideal 
load on the system, from stand point of equipment needed and operating routine, would be one of constant magnitude and steady duration.

Table 3 Probabilistic yearly load scenario

\begin{tabular}{|c|c|c|c|c|c|c|c|c|c|c|c|c|}
\hline & & & \multicolumn{10}{|c|}{ Probabilistic Yearly Loads in different bus } \\
\hline \multicolumn{3}{|c|}{ HourYearly } & \multicolumn{2}{|c|}{ Bus-2 } & \multicolumn{2}{|c|}{ Bus-3 } & \multicolumn{2}{|c|}{ Bus-4 } & \multicolumn{2}{|c|}{ Bus-5 } & \multicolumn{2}{|c|}{ Bus-6 } \\
\hline & & & $\begin{array}{c}P \\
(\mathrm{MW})\end{array}$ & $\begin{array}{c}Q \\
\text { (MVR) }\end{array}$ & $\begin{array}{c}P \\
(\mathrm{MW})\end{array}$ & $\begin{array}{c}Q \\
\text { (MVR) }\end{array}$ & $\begin{array}{c}P \\
(\mathrm{MW})\end{array}$ & $\begin{array}{c}Q \\
\text { (MVR) }\end{array}$ & $\begin{array}{c}P \\
(\mathrm{MW})\end{array}$ & $\begin{array}{c}Q \\
\text { (MVR) }\end{array}$ & $\begin{array}{c}P \\
(\mathrm{MW})\end{array}$ & $\begin{array}{c}Q \\
\text { (MVR) }\end{array}$ \\
\hline 1 & - & 425 & 6.8 & 1.1 & 6.3 & 1.9 & 7.5 & 1.5 & 5.8 & 2.6 & 9.8 & 1.6 \\
\hline 426 & - & 975 & 7.1 & 1.4 & 9.5 & 1.6 & 6.7 & 0.6 & 9.4 & 2.9 & 8.7 & 1.9 \\
\hline 976 & - & 1375 & 3.8 & 0.6 & 3.6 & 2.4 & 3.2 & 1.5 & 3.7 & 1.7 & 4.3 & 1.1 \\
\hline 1376 & - & 1800 & 9.8 & 2.1 & 9.5 & 2.4 & 9.2 & 2.1 & 9.2 & 2.5 & 9.8 & 1.1 \\
\hline 1801 & - & 2320 & 9.6 & 1.6 & 9.1 & 2.5 & 8.1 & 1.4 & 9.8 & 2.1 & 9.7 & 2.1 \\
\hline 2321 & - & 2870 & 4.7 & 1.1 & 4.2 & 1.9 & 5.7 & 1.9 & 5.8 & 1.6 & 7.7 & 1.6 \\
\hline 2871 & - & 3590 & 7.8 & 1.2 & 6.6 & 1.8 & 6.7 & 1.6 & 6.4 & 1.9 & 8.2 & 1.7 \\
\hline 3591 & - & 4120 & 9.9 & 2.1 & 9.9 & 1.9 & 9.7 & 1.8 & 9.9 & 1.7 & 9.5 & 2.6 \\
\hline 4121 & - & 4570 & 9.4 & 2.2 & 9.5 & 2.8 & 8.7 & 2.4 & 9.5 & 3.1 & 9.8 & 0.7 \\
\hline 4571 & - & 5100 & 8.7 & 1.1 & 9.6 & 1.9 & 9.4 & 1.8 & 8.1 & 1.7 & 9.6 & 1.6 \\
\hline 5101 & - & 5580 & 9.6 & 1.7 & 9.6 & 2.1 & 8.4 & 2.7 & 9.4 & 1.9 & 9.2 & 2.2 \\
\hline 5581 & - & 6025 & 5.8 & 1.4 & 7.8 & 1.6 & 8.1 & 1.7 & 8.9 & 1.8 & 8.8 & 1.9 \\
\hline 6026 & - & 6560 & 5.4 & 1.3 & 9.9 & 1.7 & 6.4 & 1.1 & 8.2 & 2.4 & 7.2 & 1.8 \\
\hline 6561 & - & 7170 & 3.7 & 0.7 & 4.5 & 2.1 & 2.4 & 0.4 & 4.5 & 2.1 & 3.2 & 1.4 \\
\hline 7171 & - & 7510 & 8.5 & 1.5 & 9.9 & 1.5 & 9.5 & 1.9 & 9.6 & 3.1 & 9.1 & 2.2 \\
\hline 7511 & - & 8110 & 9.2 & 1.8 & 9.9 & 1.2 & 9.5 & 1.3 & 8.8 & 2.2 & 9.1 & 2.3 \\
\hline 8111 & - & 8520 & 7.4 & 2.2 & 9.2 & 2.1 & 6.8 & 1.4 & 9.6 & 2.1 & 9.4 & 2.7 \\
\hline 8521 & - & 8760 & 5.1 & 1.5 & 5.3 & 1.5 & 5.5 & 1.8 & 5.1 & 1.7 & 6.7 & 2.2 \\
\hline
\end{tabular}

The variable load on a power station introduces many perplexities in its operation. Some of the important effects of variable load on a power station are increased production cost and requirement of additional equipment's to operate the system. The load duration curve is obtained from the same data as the load curve but the ordinates are arranged in the order of descending magnitudes. In other words, the maximum load is represented to the left and decreasing loads are represented to the right in the descending order. Hence the area under the load duration curve and the area under the load curve are equal. Large power system network causes voltage quality drops and higher power loss due to these natural load variations. Interconnection of DG to the grid may have different implications on the distribution network due to the load characteristics. In this research, worst possible loaddemand curve of a zone is analysed to ensure optimal placement of DG [10]. Variable load connected 6 buses are analysed on basis of their data of respective yearly load-demand curves in the network which are depicted in Table 3.

\section{System Analysis}

A power flow study or load-flow study is a steady-state analysis whose target is to determine the voltages, currents, and real and reactive power flows in a system under a given load conditions. The purpose of power flow studies is to plan ahead and account for various hypothetical situations. For example, if a transmission line is taken off line for maintenance, can the remaining lines in the system handle the required loads without exceeding their rated values. The basic power flow equations and are nonlinear. In an $n$-bus power system, let the number of $P Q$ buses be $n_{p}$ and the number of $P V$ (generator) buses be $n_{g}$ such that $n=n_{p}+n_{g}+1$. Both voltage magnitudes and angles of the $P Q$ buses and voltage angles of the $P V$ buses are unknown making a total number of $2 n_{p}+n_{g}$ quantities to be determined. Amongst the known quantities are $2 n_{p}$ numbers of real and reactive powers of the $P Q$ 
buses, $2 n_{g}$ numbers of real powers and voltage magnitudes of the $P V$ buses and voltage magnitude and angle of the slack bus. Therefore, there are sufficient numbers of known quantities to obtain a solution of the load flow problem.

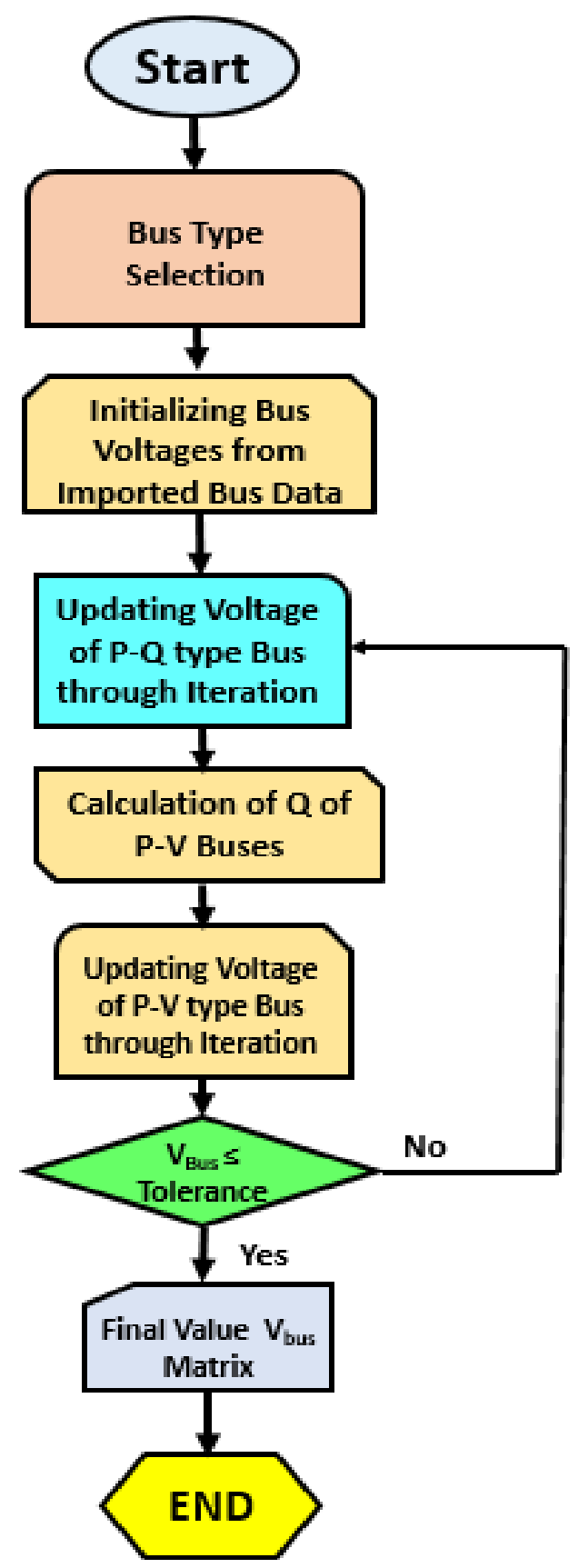

Fig. 3 Flow chart for bus voltage calculation

However, it is rather difficult to obtain a set of closed form equations from non-linear power flow equations. Therefore, algorithm has to resort to obtain iterative solutions of the load flow problem. Non-linear basic power flow equations are solved by using gauss-seidal iteration method. Self-admittance of each bus and the mutual admittance between the buses forms admittance matrix using the value of line impedances and line charging admittances of Table 1. Per unit voltage value $1+j 0$ is initialized for all buses to find-out the unknown bus voltage magnitudes and angles of the $P Q$ buses and angles of the $P V$ buses. 


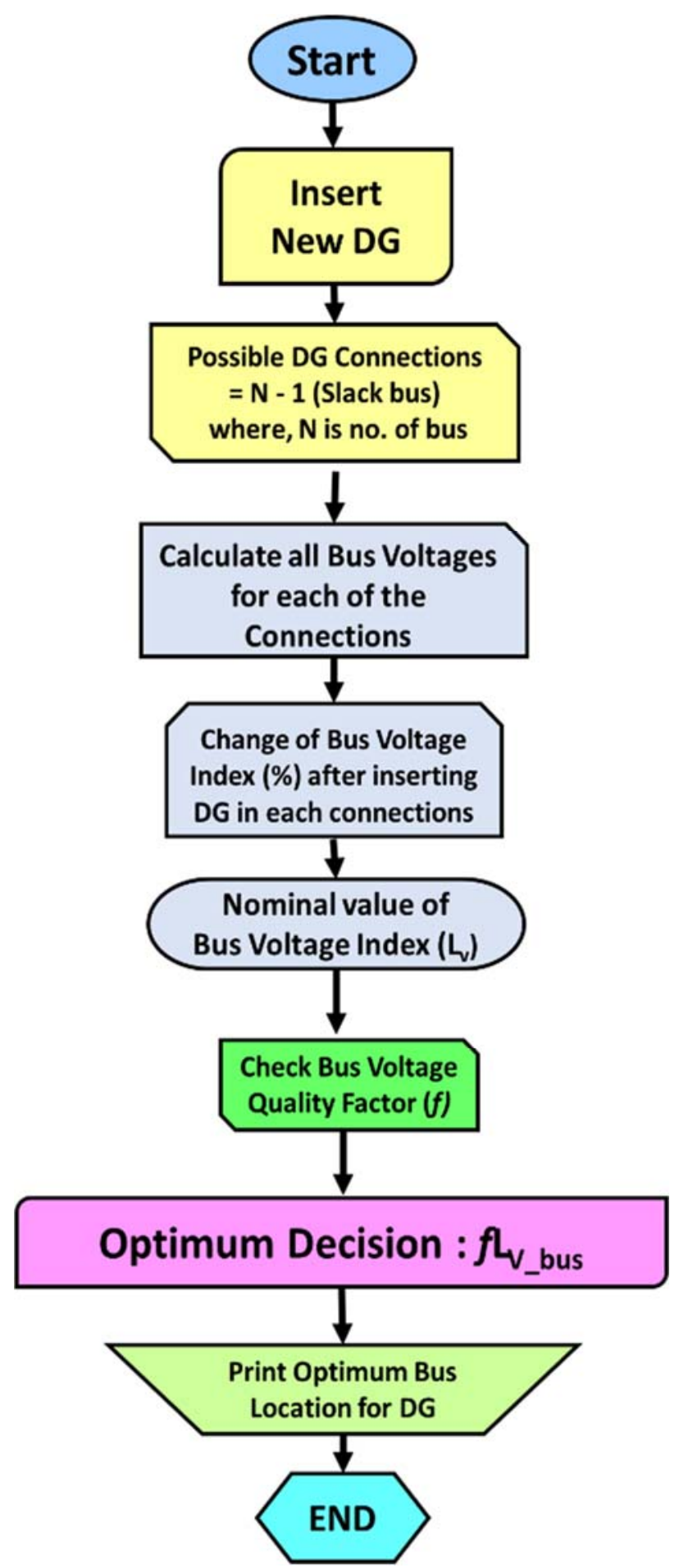

Fig. 4 Flow chart for qualitative bus voltage optimization

After convergence progress of iteration solutions final bus voltage is determined beyond the tolerance level. Voltage difference between two buses causes the current flow to the network line. The flow chart to determine the summation of all bus voltage and bus quality is depicted in Fig. 3. In the first stage of multi-objective optimization process candidate DG is placed in all available buses independently except slack bus to calculate the change of bus voltage profiles using gauss-seidal iteration method. A heuristics approach is used in the second stage through lagrangian multiplier function to find the optimal bus location for integration of DG units in a power system network. Flow chart for optimization process is depicted in Fig. 4. 


\section{Results and Discussions}

In the process of optimization selected new DG is connected to all possible bus location to find the change in bus voltage and quality with respected to normalized system values. Change of bus voltage magnitudes after DG insertion in each bus of the network except the swing bus is depicted in Fig. 5 where it is very clear that not only voltage improvement but also there are reduction of bus voltage magnitudes. Optimal bus location is selected when maximum voltage profile improvement with best possible voltage quality is ensured in the network. Total change in bus voltage and voltage quality for DG placement in each bus location is depicted in Fig. 6. Optimal bus location for the given network of dynamic loads is selected bus number 3 from the Table 4 where, it is clear that bus- 6 and bus-3 has same percentage of voltage magnitude improvement but deviation in bus voltage quality results the optimal bus location for new DG.

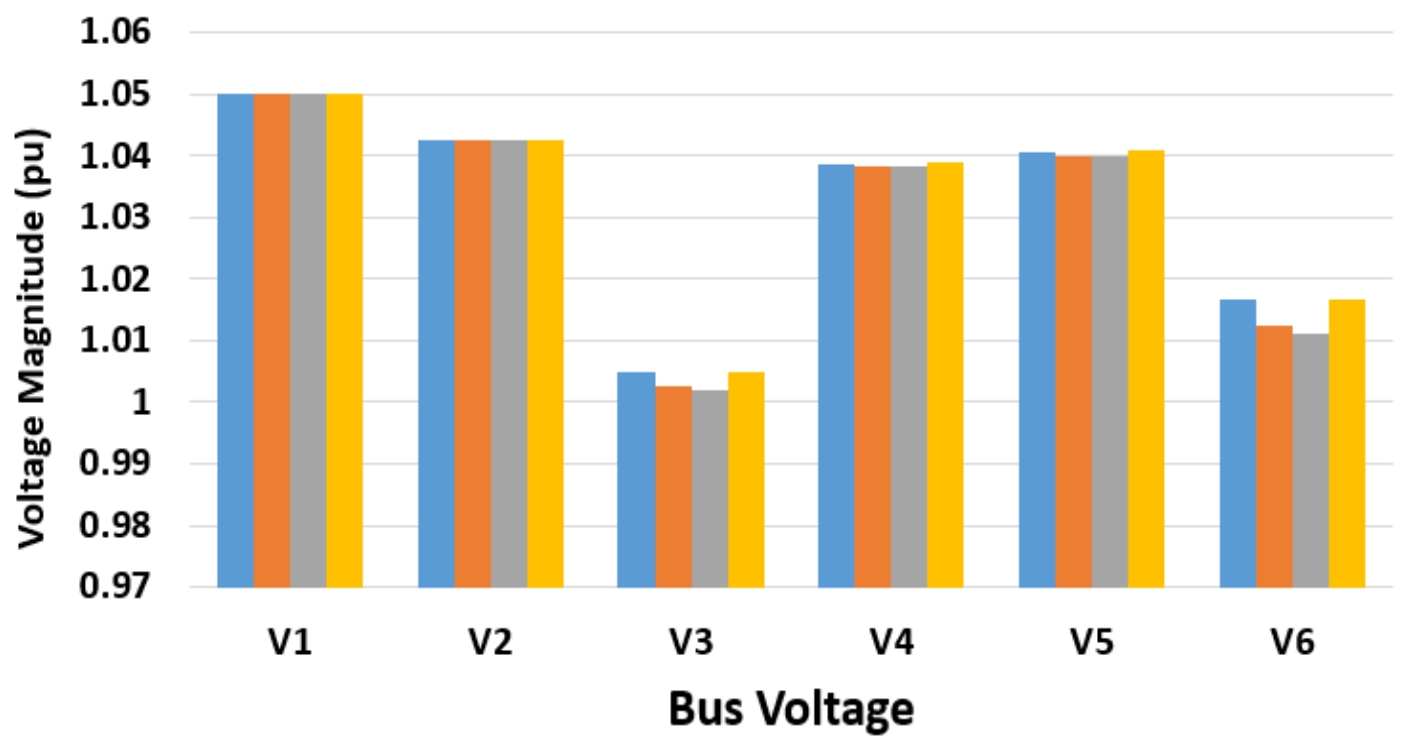

\section{Without DG DG at Bus-2 DG at Bus-3 DG at Bus-4}

Fig. 5(a) Change in each bus voltage magnitudes after DG insertion

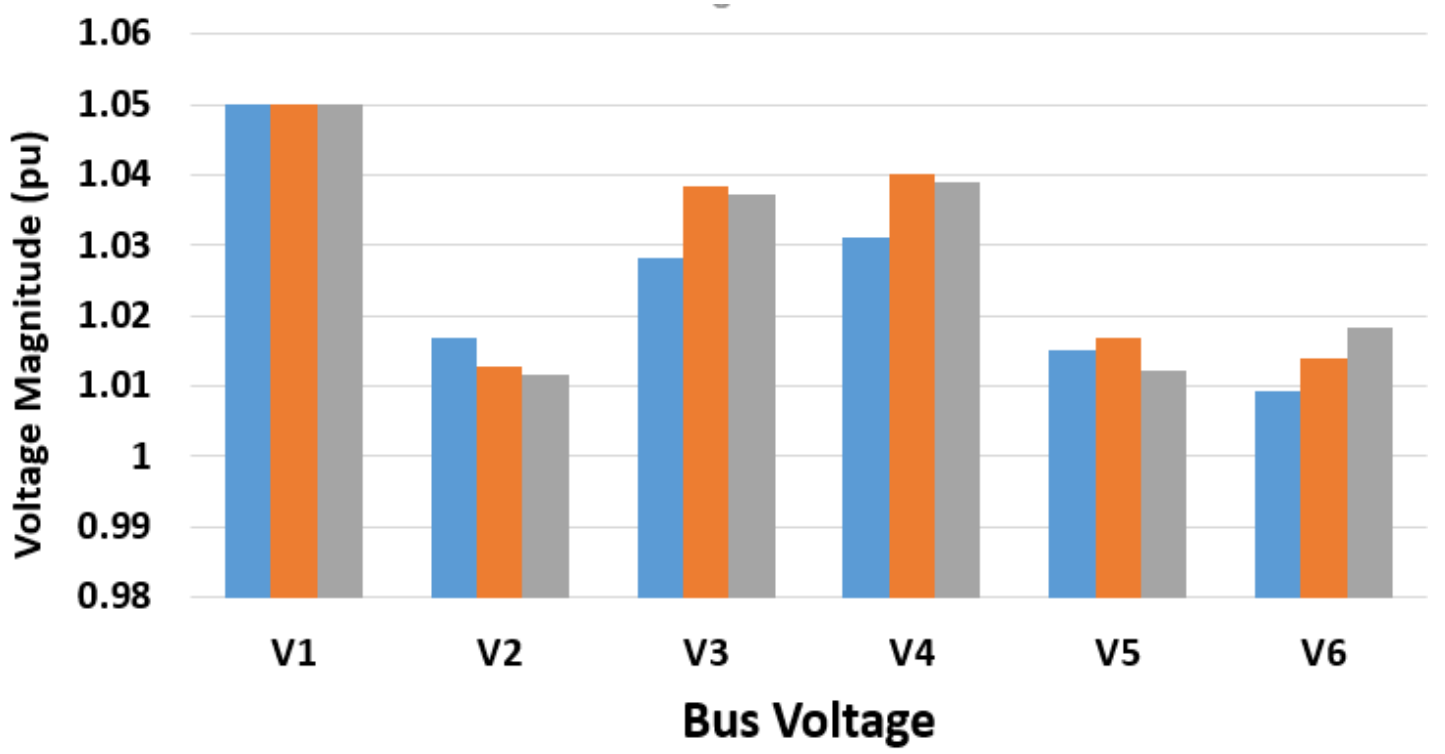

Without DG $\quad$ DG at Bus-5 DG at Bus-6

Fig. 5(b) Change in each bus voltage magnitudes after DG insertion 
1.045

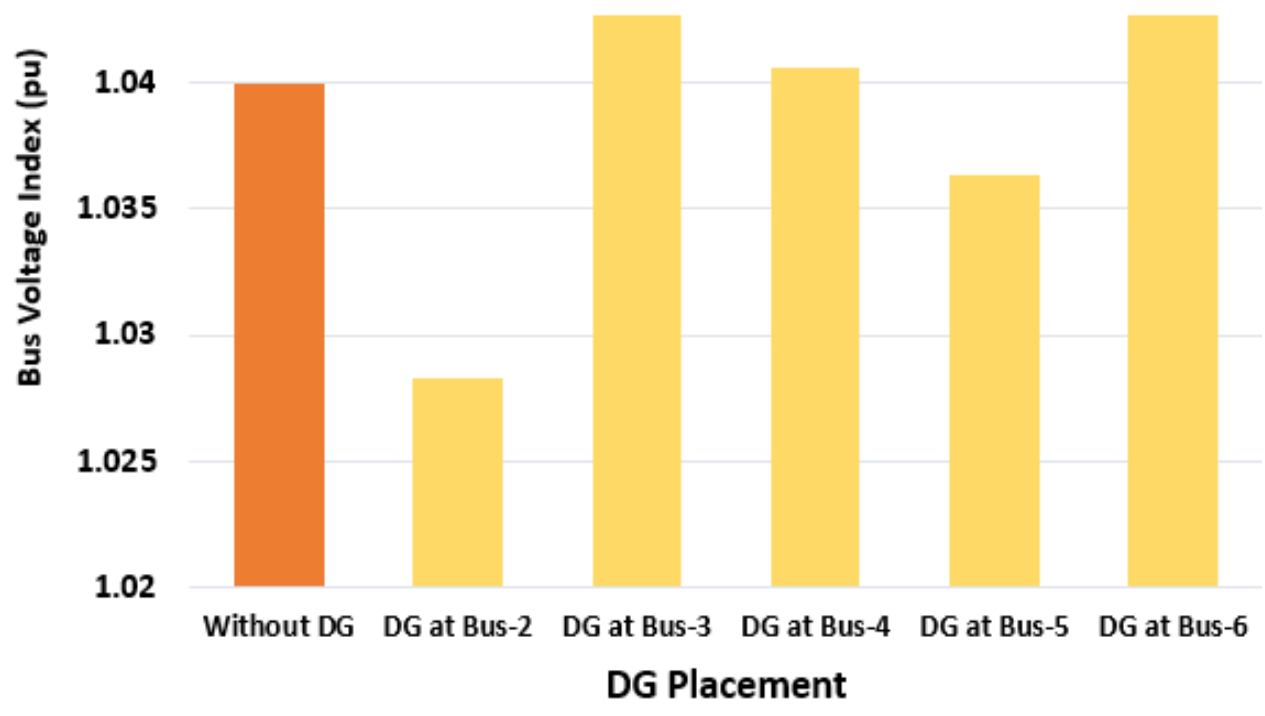

Fig. 6(a) Change in bus voltage index after DG insertion in each bus

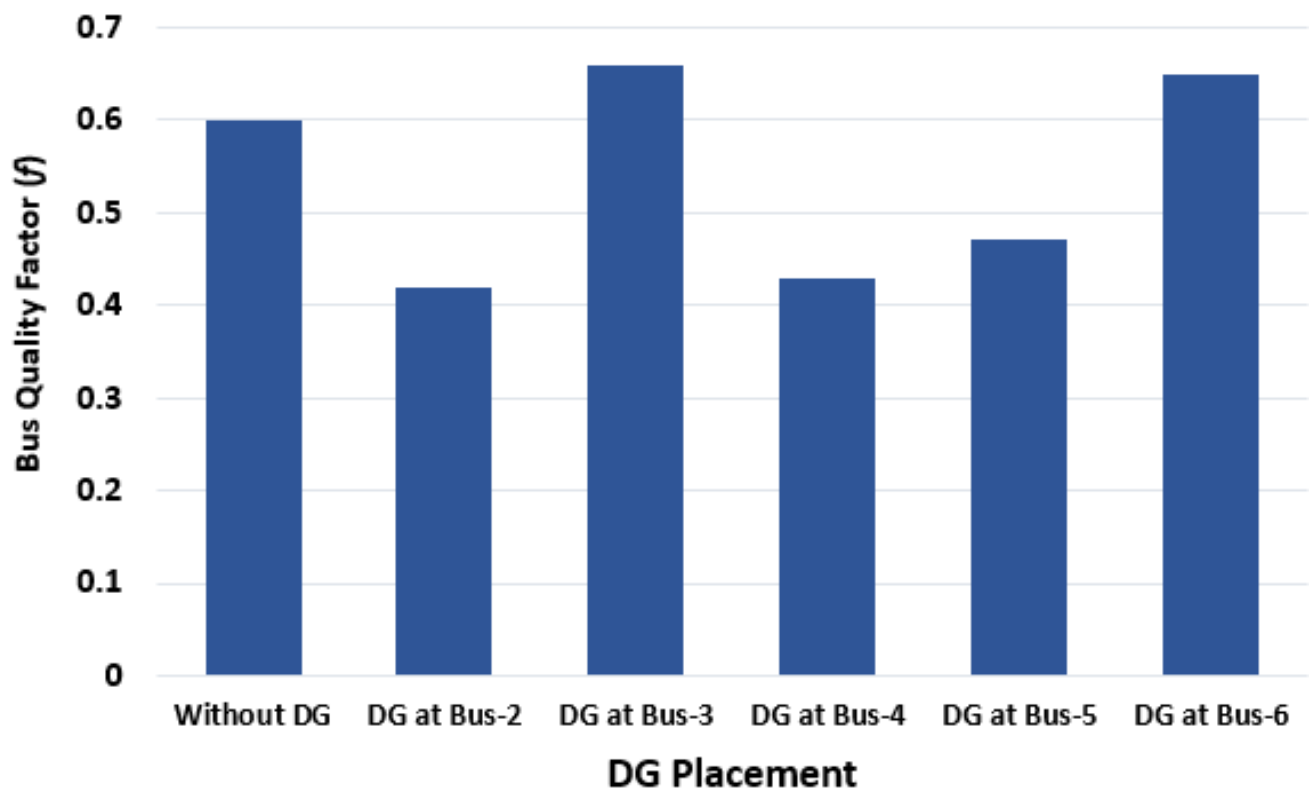

Fig. 6(b) Change in bus voltage quality after DG insertion in each bus

Table 4 Optimal bus location for DG placement

\begin{tabular}{cccc}
\hline \multirow{2}{*}{ DG Placement } & \multicolumn{2}{c}{ Total Change in \% } & \multirow{2}{*}{ Decision } \\
\cline { 2 - 3 } & Voltage $(\mathrm{pu})$ & Quality Factor $(f)$ & \\
Without DG & 1.04 & 0.60 & \\
Bus-2 & $(-) 1.13$ & 0.42 & Selected \\
Bus-3 & $(+) 0.26$ & 0.66 & \\
Bus-4 & $(+) 0.16$ & 0.43 & \\
Bus-5 & $(-) 0.35$ & 0.47 & \\
Bus-6 & $(+) 0.26$ & 0.65 & \\
\hline
\end{tabular}




\section{Conclusion}

This proposed algorithm results the enhancement of voltage magnitudes in distribution system is possible at the most qualitative bus profile after inserting DG at an optimal location of a power system network. Due to uncertain loading conditions of today's existing power system network, proposed technique analyzed time variant probabilistic load and distinguishes the divergent of DG location with satisfactory outcomes.

\section{References}

[1] H. K. Clark, “New challenges: Voltage stability” IEEE Power Engineering Review, April 2013, pp. 33-37.

[2] T. V. Custem "A method to compute reactive power margins with respect to voltage collapse, IEEE Transactions on Power Systems, Volume: 6, Issue: 1, pp. 145 - 156, Feb. 2011

[3] T. Ackermann, and V. Knyazkin 'Interaction between distributed generation and the distribution network: operation aspects' IEEE PES Transmission and Distribution Conference and Exhibition, vol. 2, 2002, pp. 1357- 1362.

[4] U. T. Varshitha and K. Balamurugan 'Optimal Placement of Distributed Generation with SVC for Power Loss Reduction in Distributed System’ ARPN Journal of Engineering and Applied Sciences, Vol. 12, No. 17, pp. 4895-4901, Sep 2017.

[5] M. M. S. Mora, C. A. Tamayo and J. M. López-Lezama "Optimal Allocation of Distributed Generation for Improving Chargeability and Voltage Profile under Different Operative Scenarios” Contemporary Engineering Sciences, Vol. 11, no. 51, pp. 2503 - 2511, 2018.

[6] M. Sriramulu, M. R. Rahul “Optimal Placing and Sizing of DG in a Distribution System for Voltage Stability Improvement” International Conference on Electrical, Electronics, and Optimization Techniques, 2016, pp. 1469-1475.

[7] M. E. Baran, and El-Markabi, "A multi-agent based dispatching scheme for distributed generators for voltage support on distribution feeders," IEEE Transactions on Power Systems, vol. 22, Issue-1, pp. 52-59, 2007.

[8] A. Alsaadi, and B. Gholami “An Effective Approach for Distribution System Power Flow Solution” International Journal of Electrical and Computer Engineering, vol. 3, No.1, pp. 1-5, 2009.

[9] J. R. W. Stevenson and J. Grainger ‘Power System Analysis’ 1st Edition 1994, pp. 324-365.

[10] A. Keane, L. F. Ochoa “State-of-the-Art Techniques and Challenges Ahead for Distributed Generation Planning and Optimization” IEEE Transactions on Power System, vol. 28, no. 2, pp. 1493-1502, 2013. 